\title{
O DISCURSO XENÓFOBO E A GEOPOLÍTICA MUNDIAL: DESDOBRAMENTOS ANALÍTICOS, OLHARES EDUCACIONAIS E INTERFACES POSSÍVEIS
}

\author{
Rafael Teixeira de Paula Lima ${ }^{\mathrm{i}}$ \\ Joyce Pedra de Paula Lima ${ }^{\text {ii }}$
}

\begin{abstract}
Resumo: Diante de uma reconfiguração patente de antigos paradigmas comunicacionais, marcadamente reajustados na clave das redes sociais, a política ganha novas facetas e novos contornos. No âmbito da geopolítica, tais dimensões colocam desafios analíticos, sobretudo, das fake news contemporâneas e de uma xenofobia que ganha força e gera danos colaterais à diplomacia nacional. A presente investigação, nesta medida, tem como objetivo discutir tal conjunção de fenômenos e refletir sobre tais questões baseando-se nos desdobramentos advindos de uma percepção do multiculturalismo e suas derivações educacionais. Metodologicamente, optou-se pelo cotejo de peças das principais redes sociais nas quais uma interseção entre geopolítica e discurso gerassem frutos analíticos.
\end{abstract}

Palavras-chave: Geopolítica; Educação; Xenofobia; Fake news.

\section{XENOPHOBIC DISCOURSE AND WORLD GEOPOLITICS: ANALYTICAL DEVELOPMENTS, EDUCATIONAL VIEWS AND POSSIBLE INTERFACES}

\begin{abstract}
In the face of a patent reconfiguration of old communication paradigms, markedly seen in the social networks, politics gains new facets and new contours. In the context of geopolitics, such aspects pose analytical challenges, mainly contemporary "fake news" and xenophobia, that gains strength and generates damage caused by national diplomacy. The present investigation, in this aspect, aims to discuss the conjunctions of phenomena and reflect on these issues based on the developments arising from a perception of multiculturalism and its educational derivations. Methodologically, the option to collect pieces from the main social networks in which an intersection between geopolitics and discourse would generate analytical fruits was chosen.
\end{abstract}

Keywords: Geopolitics; Education; Xenophobia; Fake news

\section{Prolegômenos a um tempo de crise}

Em um período de distanciamento social, em meio à maior pandemia desde a segunda metade do século XX - o COVID-19 - fomos, ainda mais, expostos à um intenso fluxo de informações. No meio de tantas notícias, e entre elas as conhecidas e ferozmente divulgadas fake news, nos deparamos com outro grande desafio em relação às informações sobre o novo coronavírus: as mensagens que estimulam o racismo, a xenofobia, o nacionalismo exacerbado e o ódio. O agravante dessa situação é que, muitas vezes, essas perspectivas são propagadas por chefes de Estado e/ou representantes políticos, não só no Brasil, mas no mundo. Torna-se uma missão, no âmbito da educação, a abordagem e discussão sobre esta 
conjuntura que vem se delineando em meio à pandemia. A análise destes discursos perpassa por todas às áreas e níveis educacionais, sendo necessário abordá-la desde da educação básica, não só, mas, principalmente, nas áreas das ciências humanas e na linguística, especificamente, na análise do discurso.

De maneira ampla, pode-se afirmar que a sociedade tem ficado cada vez mais sensível às questões de representatividade e aflorada para os imbróglios políticos, envolvendo-se nas discussões vinculadas à microfísica do poder e aos desdobramentos de sua atualização. Pode-se afirmar, sobretudo, com bastante pertinência e razoabilidade, que o sujeito contemporâneo, em solo nacional, tem se imiscuído, democraticamente, aos seus pares para exercer com maior propriedade seu papel de cidadão. Por outro lado, é de suma importância reconhecer uma particularidade de tal movimento sociocultural, se assim pudéssemos concebê-lo. O movimento que se deseja trazer à tona tem cunho antagônico e agônico - em uma infeliz similitude terminológica. Antagônico porque diz respeito a uma força que, contrária à expansão de uma consciência política e apropriação democrática dos meios sociais, trabalha a favor da obnubilação dos fatos, do escurecimento conceitual e do ofuscamento do real. Agônico, porque inconcebível e agressor de princípios fundamentais para o bem-estar nacional.

Esse movimento, firmado na cabal incompatibilidade com a democracia e que carrega consigo as marcas da hostilidade e do fomento ao conflito, reverbera na linguagem seus traços e, por meio dela, causa danos - quem dirá, irreversíveis - às mais variadas instâncias do cenário público. Seja por meio da rearticulação terminológica ou de uma transmutação de informações, com viés perverso - a chamada fake news - ou simples mobilização de termos ofensivos para com aqueles que conosco firmam laços de amizade no âmbito da política internacional.

Aqui, antes de qualquer incursão mais direcionada, caberia evidenciar e esclarecer a importância do conceito de fake news para posterior desdobramentos nesta investigação. O termo se coloca numa realidade marcadamente estabelecida no chamado período de pós-verdade ${ }^{\mathrm{iii}}$ e remonta à hermenêutica nietzschiana quando, propondo o protagonismo das versões em detrimento dos fatos, a busca pela verdade se vê colocada em difícil enquadramento teórico-filosófico. Em Foucault, tais questões encontram seus desdobramentos sociais e são observados pelas lentes das teorias da dissonância cognitiva nos âmbitos especialmente políticos, enriquecendo o debate das ciências humanas como um todo (GÓIS, 2012, p. 110). Ora, uma fake news, portanto, pode ser conceituada como uma mobilização deliberada, por meio de determinada mídia, de desinformação e/ou difamação.

Nesta medida, ao pesquisador desejoso de um país melhor, mais consciente e democrático, resta o dever da investigação criteriosa, a fim de, respaldado pela pesquisa, oferecer à sociedade insumos de reflexão e, por conseguinte, ação. Deriva-se de tal discussão que essa luta, sendo travada no campo das ideias e no solo da linguagem, exige de seus combatentes formação primorosa e educação responsável. O que pensar da educação diante do cenário ao qual nos referimos? Qual o seu papel, enquanto garantidora 
da liberdade democrática que encontra nessa mesma educação seu sustentáculo? Perguntas como essas garantem profundas possibilidades investigativas e incursões teóricas àqueles que aspiram por um futuro aprazível e salutar.

\section{Breve contextualização sobre o aumento da xenofobia no brasil e no mundo}

A xenofobia, sentimento de preconceito e aversão contra os imigrantes e/ou povos de diferentes culturas, etnias ou crenças, é um sentimento que, nos últimos anos, vem crescendo tanto no Brasil, quanto no mundo. O referido sentimento segue em sentido oposto ao processo de globalização, que tem como base a ideia de integração, apesar de, ser clara a concepção, que o termo refere-se muito mais ao viés econômico do que social. Se por um lado as economias tendem a ficar mais integradas, via comércio mundial e meios de comunicação, por outro lado, devido às próprias crises econômicas, mais Estados tendem a fechar as suas fronteiras aos indivíduos estrangeiros.

Tal perspectiva explicitou-se no mundo com a crise migratória na Europa, que teve o seu auge em 2015. O pavor in extremis da chegada em massa de imigrantes e com eles a interpretação de agravamento da crise econômica e a, generalização descabida, de que indivíduos muçulmanos (ou provenientes de países/regiões onde a crença é predominante) eram potencialmente terroristas, explodiu a xenofobia em diversas parcelas da sociedade europeia. O processo do Brexit ${ }^{\mathrm{iv}}$, votado em 2016 no Reino Unido, e a eleição de diversos chefes de Estado de extrema direita no mundo, são reflexos deste processo. Nos Estados Unidos, o discurso contra os imigrantes foi um dos pontos decisivos para a eleição de Donald Trump, em 2016. No Brasil, o sentimento xenófobo foi evidenciado com a intensificação da imigração de venezuelanos, devido à crise econômica e política no país vizinho. Tal situação gerou atos e falas de hostilidade contra os imigrantes por parcela da população brasileira, e de alguns representantes políticos do país. Santos (SANTOS, 2016, p. 8) aborda este sentimento e atos em seu trabalho:

Esse preconceito de classe se expressa em comportamentos que beiram o fascismo, destilando discursos de ódio e de repulsa ao "diferente", ao/à estrangeiro/a, ao não familiar, vistos como ameaça à uma pretensa estabilidade da "ordem" e da economia mundiais. (SANTOS, 2016, p. 8)

Os processos supracitados criaram bases sólidas em diversas partes do mundo, e no Brasil, para que declarações xenófobas fossem naturalizadas e justificadas, via argumentações de cunho econômico e de segurança nacional. Tais declarações ocorrem, em grande parte dos casos, sem quaisquer embasamentos técnico/científico que pudessem subsidiar os referidos posicionamentos. Neste cenário ocorre a pandemia da Covid-19, que tem ceifado vidas e colapsado o sistema de saúde em diversas partes do globo. No processo de evolução da doença, fronteiras foram fechadas e, em muitos casos, imigrantes 
culpabilizados pelo espalhamento do vírus. Contudo, muitos cidadãos nativos em viagem, sem o conhecimento do nível de gravidade da doença, e da sua própria contaminação, também levaram, sem saber, o vírus para seus países-natais.

Milton Santos (SANTOS, 2006, p. 56) ressalta a importância das soluções cooperadas em detrimento às visões individualistas, que não geram, a longo prazo, resultados efetivos.

A consciência da diferença pode conduzir simplesmente à defesa individualista do próprio interesse, sem alcançar a defesa de um sistema alternativo de ideias e de vida. De um ponto de vista das ideias, a questão central reside no encontro do caminho que vai do imediatismo às visões finalísticas; e de um ponto de vista da ação, o problema é ultrapassar as soluções imediatistas (por exemplo, eleitoralismos interesseiros e apenas provisoriamente eficazes) e alcançar a busca política genuína e constitucional de remédios estruturais e duradouros. (SANTOS, 2006, p.56)

O aumento no número dos casos de Covid-19 no mundo foi acompanhado pelo crescimento simultâneo de discursos e posicionamentos xenófobos, tendo a princípio os asiáticos, em destaque os chineses, como alvo da intolerância. Em reportagem, do dia 28 de março de 2020, a revista Carta Capital abordou o tema, ressaltando os resultados de um estudo israelense que apontou o absurdo crescimento de 900\% nas mensagens de ódio contra a China, e os chineses de forma geral, na rede social Twitter.

As pessoas passam cada vez mais tempo nas redes sociais e em aplicativos de mensagens e jogos, e os problemas endêmicos dessas plataformas, como o ódio, abuso, toxicidade e intimidação, acentuaram-se', assinala a empresa L1ght[sic], com sede em Israel, em seu relatório. Carta Capital (2020)

Além do aumento nas mensagens ofensivas na referida rede social, segundo o mesmo estudo, a visita em sites de conteúdos que disseminam o ódio aumentou 200\%. O trabalho afirma que esse tipo de posicionamento encontra respaldo em alguns veículos de mídia e nos discursos de autoridades. Sobre a questão da mídia, o relatório deste estudo cita um vídeo do canal Sky News Austrália com o título "A China infligiu voluntariamente o coronavírus ao mundo", que gerou diversos comentários de cunho xenofóbico. Sobre os discursos de autoridades o relatório menciona as falas do presidente Donald Trump, que se refere ao novo coronavírus como "vírus chinês".

$\mathrm{O}$ crescimento da intolerância, frente à pandemia, tem preocupado a Organização das Nações Unidas (ONU). O secretário-geral da organização, António Guterres, afirmou que tal processo configura um "tsunami de ódio e xenofobia" e que o mundo precisa agir imediatamente para "fortalecer a imunidade das nossas sociedades contra o vírus do ódio" (ONU-Brasil, 2020). Guterres fez um apelo às lideranças mundiais no combate à xenofobia e intolerância: 
É por isso que hoje apelo a um esforço conjunto para acabar com o discurso de ódio globalmente. Apelo aos líderes políticos que demonstrem solidariedade para com todos os membros das suas sociedades e construam e reforcem a coesão social. (ONU-Brasil, 2020).

O secretário-geral, na mesma fala, destacou a importância da atuação das instituições de ensino no enfrentamento às posturas de ódio e de intolerância, ressaltando que

num momento em que milhares de milhões de jovens navegam na internet e que extremistas procuram explorar um público que está potencialmente confinado e desesperado. (ONU-Brasil, 2020).

Assim, reforça-se o papel da educação, como meio de conhecimento e conscientização, no combate ao radicalismo e à ignorância, que baseiam os posicionamentos xenófobos e discriminatórios de forma geral. A apresentação e discussão desta temática é imprescindível para a formação de cidadãos capazes de tornar a realidade e a sociedade mais justas e solidárias. Esta abordagem permeia diversos conteúdos escolares e acadêmicos, e a educação, para tornar-se significativa, deve contemplar a realidade dos indivíduos. A realidade que se apresenta no momento, em nível mundial, é o enfrentamento do Covid-19 e os desafios advindos desta pandemia.

A História relata como processos discriminatórios, opressivos e os discursos de ódio produziram terríveis consequências ao longo dos tempos, responsáveis por enormes tragédias sociais e humanitárias. Desta forma, a educação é a principal arma para combater a intolerância, que se apresentou como um grave efeito colateral da pandemia. No próximo tópico o presente trabalho intentará apresentar possibilidades de reflexão e discussão a serem trabalhadas na educação, a partir de análises discursivas e geopolíticas, de falas preconceituosas de figuras políticas brasileiras, no contexto da pandemia do Covid19.

\section{Análises de discursos e posicionamentos xenófobos de figuras políticas nacionais}

Conforme exposto, com o avanço da pandemia, aumentou também os casos de xenofobia no mundo. Tal situação é agravada pelo fato de que figuras políticas expuseram posicionamentos xenófobos, e estes indivíduos são, ou pelo menos deveriam ser, referências para a população, visto que a representam. Quando discursos de intolerância e ódio são proferidas por lideranças, esta situação gera uma impressão de legitimação do ato.

No Brasil, o deputado federal, presidente da Comissão de Relações Exteriores da Câmara dos Deputados, e também filho do presidente, Eduardo Bolsonaro, fez um post em seu Twitter com a seguinte mensagem: 
Quem assistiu Chernobyl vai entender o q ocorreu. Substitua a usina nuclear pelo coronavírus e a ditadura soviética pela chinesa.

+1 vez uma ditadura preferiu esconder algo grave a expor tendo desgaste, mas q salvaria inúmeras vidas.

A culpa é da China e liberdade seria a solução

BOLSONARO, Eduardo (BolsonaroSP).18 mar. 2020, 14:38. Tweet.

Se observamos com maior rigor analítico o texto em questão, alguns elementos devem ser considerados no âmbito da análise discursiva. Primeiramente, caberia ter em vista que a relação entre os interlocutores - enunciador e enunciatário, é assimétrica. Eduardo Bolsonaro se dirige a um público irrestrito alocando um referente marcadamente sensível, em termos políticos, para a nação. Essa ausência de prudência, firmada pelo discurso em questão, recebe seu corolário quando observa-se que a enunciação se dá por meio de dois eixos imagéticos que podem ser decompostos como se segue: a) Chernobyl/ Coronavírus; b) Ditatura Soviética -> Ditadura Chinesa.

Assim, para entender o COVID-19 é mister entender Chernobyl, tendo em vista que, se no âmbito soviético o valor semântico de Chernobyl é vinculado à União Soviética - e negativo por excelência, o mesmo deriva do valor semântico da COVID-19, vinculando-se à China. A interseção de tais perspectivas se estabelece no termo ditadura, que absorve e centraliza em si as dimensões negativas de União Soviética/China, Chernobyl, COVID-19 e, claro o antagonismo velado que surge ao fim do texto, entre liberdade/vida, interdição/morte (cf. CHARAUDEAU, 2006). Em uma avaliação dos instrumentos persuasivos, essencialmente pela clave dos espaços mentais (cf. FAUCONNIER, 2002), estrategicamente geridos pelo enunciador, fica evidente a dimensão patética ${ }^{\mathrm{v}}$ do discurso e ausente de qualquer rigor lógico-formal.

Esta postagem acusa diretamente o nosso maior parceiro comercial de responsabilidade pelo vírus e sua disseminação. O caso é grave em vários sentidos. Primeiro, por estimular a xenofobia e o ódio contra outro povo e país, em um momento em que as lideranças deveriam desencorajar tais posicionamentos, por questões éticas, diplomáticas, legais e morais. Segundo, coloca o Brasil em desconforto diplomático com o maior comprador de produtos brasileiros. Além da crise de saúde, a pandemia provocou também uma enorme recessão econômica, assim, precisamos e precisaremos, ainda mais, preservar bons laços diplomáticos e econômicos com a China.

O embaixador chinês no Brasil, Yang Wanming, rechaçou a postagem de Eduardo e exigiu retratação:

A parte chinesa repudia veementemente as suas palavras, e exige que as retire imediatamente e peça uma desculpa ao povo chinês. Vou protestar e manifestar a nossa indignação junto ao Itamaraty e a @camaradeputados. @BolsonaroSP@ernestofaraujo@RodrigoMaia.

WANMING, Yang (WanmingYang). 18 mar. 2020, 21:55. Tweet. 
Segundo Sá (2020), a mídia chinesa, através do Global Times/Huanqiu, também reagiu negativamente à mensagem de Eduardo Bolsonaro, em que trouxe na edição digital do veículo de comunicação a manchete: "Palavras racistas de Trump provocam ódio e alimentam xenofobia global", referindo-se à postagem do deputado.

Após o constrangimento da publicação de Eduardo Bolsonaro, visto a extrema importância da China como parceira comercial, vários representantes políticos brasileiros, inclusive o próprio presidente, pai do deputado, declararam que a fala de Eduardo não representava o posicionamento oficial do país. Esta moderação no desconforto diplomático foi relatada na mídia chinesa pelo Global Times:

\begin{abstract}
According to members of Brazilian press, Brazilian President Jair Bolsonaro was dissatisfied over his son's unfriendly remarks on China and has reprimanded the younger Bolsonaro over the matter. Brazilian Senate President DaviAlcolumbre and President of the country's Chamber of Deputies Rodrigo Maia have also issued apologies to the Chinese government and people on Twitter on Thursday, criticizing the inappropriate remarks that Eduardo Bolsonaro made, which run contrary to the significance of the China-Brazil strategic partnership. Alcolumbre, who has tested positive for the coronavirus, said, "Isolated reactions don't represent the nation's sentiment," in the name of the Brazilian parliament on Twitter. "On behalf of the Chamber of Deputies, I apologize to China and [Chinese] Ambassador Yang Wanming for the thoughtless words of Congressman Eduardo Bolsonaro," tweeted Maia. "I hope that soon we can come out of the current crisis even stronger," he said". AIXIN, Li (2020).
\end{abstract}

Além da postagem no Twitter do embaixador chinês no Brasil, Yang Wanming, o Twitter oficial da embaixada da China também replicou a mensagem do deputado:

As suas palavras são extremamente irresponsáveis e nos soam familiares. Não deixam de ser uma imitação dos seus queridos amigos. Ao voltar de Miami, contraiu, infelizmente, vírus mental, que está infectando a amizades entre os nossos povos.

Embaixada da China no Brasil (EmbaixadadaChina). 18 mar. 2020, 22:54. Tweet.

Contudo, a resposta, via Twitter, da Embaixada Chinesa também fugiu aos protocolos esperados em relações diplomáticas entre dois grandes Estados. A mensagem demonstrou uma catarse ao post ofensivo de Eduardo Bolsonaro. Tal situação apresenta a perigosa dinâmica dos discursos permeados de intolerância: a possibilidade iminente de gerar acirramento de tensões e de ressentimentos entre povos e países.

Em contrapartida a lógica da situação, que se esperaria um posicionamento de apaziguamento entre as partes, o ministro das Relações Exteriores, Ernesto Araújo, apesar de ter afirmado que as declarações de Eduardo Bolsonaro não representavam a posição do governo, julgou a reação do embaixador como "desproporcional". O ministro chegou a postar uma nota cobrando uma retração do embaixador chinês, Yang Wanming. 
É inaceitável que o embaixador da China endosse ou compartilhe postagem ofensiva ao Chefe de Estado do Brasil e aos seus eleitores, como infelizmente ocorreu ontem à noite.

As críticas do Deputado Eduardo Bolsonaro à China, feitas também em postagem ontem à noite não refletem a posição do governo brasileiro.

Cabe lembrar, entretanto, que nenhum momento ele ofendeu o Chefe de Estado chinês. A reação do embaixador foi, assim, desproporcional e feriu a boa prática diplomática.

Já comuniquei ao Embaixador da China a insatisfação do governo brasileiro com o seu comportamento. Temos a expectativa de uma retratação por sua repostagem ofensiva ao Chefe de Estado.

O Brasil quer manter as melhores relações com o governo e o povo chinês, promover negócios e cooperação em benefício recíproco, sem jamais deixar de lado o respeito mútuo.

Conversarei com o Deputado Eduardo Bolsonaro e com o Embaixador da China, procurando promover um reentendimento recíproco.

Ministro das Relações Exteriores

Ernesto Araújo

ARAÚJO, Ernesto (ernestofaraujo). 19 mar. 2020, 14:05. Tweet.

A situação foi amenizada, posteriormente, por um telefonema entre os dois chefes de Estado, segundo o presidente Jair Bolsonaro. Contudo, passado pouco mais de um mês, o ministro das relações exteriores postou um texto no site Metapolítica, associando o coronavírus a um "projeto globalista" que seria o "novo caminho do comunismo", criando, novamente, um ruído diplomático com a China.

Em um ambiente já sensível, inclusive pela forma em que o ministro conduziu a tensão a partir das colocações do deputado Eduardo Bolsonaro, a publicação de um texto com o título "Chegou o Comunavírus", é, no mínimo, desnecessária no atual contexto geopolítico. Apesar do texto não se referir diretamente à China traz elementos que podem sim, serem ofensivos ao país, pelo próprio título e por menções como:

"o comunismo [comunismo, aqui no sentido do socialismo - sistema adotado pela China] de outrora, que instalava ora num país, ora noutro, um sistema de planejamento econômico central, sempre fracassado em proporcionar bem-estar, sempre exitoso em controlar e oprimir a sociedade."

ARAÚJO, Ernesto (2020)

Tal proposição associa a China a um Estado opressor, e fracassado em promover o bem-estar da sua população. Asserção pouco amistosa e diplomática com um país já ofendido por representantes brasileiros, e que representa a maior parceria comercial do Brasil.

Outra figura pública brasileira a criar constrangimento perante às relações diplomáticas entre Brasil e China foi o ministro da educação, Abraham Weintraub. No dia 4 de abril o ministro, pela rede social Twitter, zombou do sotaque chinês e insinuou que crise gerada pelo Covid-19 seria benéfico para a China. A zombaria utilizou uma imagem do gibi da Turma da Mônica, criando uma analogia entre a 
forma de falar do Cebolinha, personagem que troca a letra $\mathrm{r}$ pela 1 e o modo de pronúncia dos chineses ao falar português.

"Geopolíticamente[sic], quem podeLásaiLfoLtalecido, em teLmosLelativos, dessa cLise mundial? PodeLiaseL o Cebolinha? Quem são os aliados no BLasil do plano infalível do Cebolinha paLadominaL o mundo? SeLia o Cascão ou há mais amiguinhos?’vii

WEINTRAUB, Abraham apud CILO, Hugo (2020)

A análise discursiva da enunciação supracitada, evidencia-se forte teor preconceituoso estabelecido por meio do colocar-se em evidência particularidades/dissonâncias fonêmicas do idioma chinês. Assim, estabelece-se dupla ancoragem: se, por um lado, vincula-se a dicotomia China/Erro, por outro firma-se a perspectiva Cebolinha/Comédia. O cruzamento destes espaços mentais configura, agressivamente, China como algo imiscuído em jocosidade. Tal configuração, de valor semântico extremamente agressivo, fere a integridade linguística e moral dos enunciatários e, sobretudo, daquele referente do qual se fala. Notadamente, o embaixador chinês repudiou as falas de mais um representante da política brasileira causar desconforto diplomático com o país, chamando-a de "palavras racistas". Em perspectivas mais sutis, nota-se, ainda, alguns elementos que surgem passíveis de interpretação. Primeiramente, as insinuações sobre possíveis vantagens aferidas pela China - o Cebolinha, na transposição imagética oferecida pelo enunciador - na pergunta retórica estabelecida em "quem poderá sair fortalecido em termos relativos desta crise mundial?"; e, em segundo lugar, a atribuição irônica de “infalível” que, em sua sutileza, ofende duplamente: pelo seu teor e pela suposta configuração que vilipendia o intelecto do enunciatário.

A estigmatização e culpabilidade de um povo e/ou Estado não resolvem o desafio imposto pela pandemia, pelo contrário, dificultam a tomada de decisões em conjunto, necessária para uma crise sanitária e econômica de proporções globais.

Além da questão ética e moral envolvida em atos de discriminação e discursos de ódio, há também as implicações comerciais e econômicas envolvidas em um mundo de economia globalizada. O próprio combate ao vírus demanda uma rede de apoio e troca de informações entre as nações, como pesquisas cooperadas na busca de uma vacina e/ou remédio para tratamento e prevenção contra o vírus; comércio de equipamentos e insumos médicos; intercâmbio de experiências e, até mesmo, de profissionais, para auxiliar locais que apresentem mais dificuldades em lidar com o problema. Além disto, por se tratar de um vírus de rápida e intensa propagação, não adiantará combater o vírus em localidades restritas, mas sim a partir de um movimento de cooperação mundial, já que, mostra-se improvável, em uma economia globalizada, manter-se por tempo indeterminado fronteiras e mercados fechados. Enfim, são diversas as 
situações que demonstram a importância da reciprocidade entre os Estados e nações, na busca de vencer este novo e inesperado desafio imposto ao mundo nos últimos meses.

\section{Incursões à educação}

A educação é um direito fundamental, garantido pela constituição brasileira que, em seu texto, destaca a importância deste direito no preparo do indivíduo para o exercício da cidadania. A educação promove o desenvolvimento social, a possibilitar romper - ou pelo menos flexibilizar a cruel a estrutura social de segregação racial e econômica, existente no Brasil e no mundo. O indivíduo escolarizado, além de mais consciente dos seus deveres, é mais atuante na reivindicação dos seus direitos, na defesa da liberdade, da democracia e da justiça, pois só conhecendo os processos de dominação é possível lutar para derrotá-los.

É, ou pelo menos deveria ser, função das instituições de ensino, em especial da educação básica, a abordagem de temáticas políticas no dia-a-dia das salas de aula. No geral, tal assunto é efetivamente vivenciado apenas nas instituições de ensino superior e, sobretudo, de forma mais factual, nas universidades públicas. Tal situação afasta as crianças e jovens de uma consciência cidadã e da sua importância na construção do futuro e de um mundo mais justo. A edificação da cidadania perpassa pelo discernimento político, capaz de tornar o indivíduo perceptivo às necessidades da sua sociedade, aos engodos de palanques eleitorais e ao engajamento do bem comum. "Não há nada que mais contradiga e comprometa a emersão popular do que uma educação que não jogue o educando às experiências do debate e da análise dos problemas e que não lhe propicie condições de verdadeira participação" (FREIRE, 1967, p. 93).

O compromisso com a construção da cidadania e consciência política deve ser uma prática contextualizada nas instituições de ensino fundamental e médio, possibilitando aos jovens arcabouço para atuarem significativamente na sociedade. Esta prática não deve, como já abordado no texto, ser limitada a uma área ou disciplina específica.É, sim, uma temática basilar às ciências humanas e à linguística, especificamente, na interpretação textual e em seus desdobramentos analíticos, que possibilitam aos alunos maior crítica e rigor diante da textualização e, claro, a compreensão de sua dimensão social. O estudo dos gêneros textuais, como sistematiza Bakhtin (2010), ganham importância exatamente no momento em que o texto se atualiza no social, isto é, em suas tramas, cujas dimensões são complexas por natureza. O domínio da linguagem perpassa não só pelo conhecimento do código linguístico, mas avança para a sua real aplicação no cenário enunciativo. Já na perspectiva geográfica, os autores Brabant (BRABANT, 2008, p. 19) e Straforini (STRAFORINI, 2008, p. 51) destacaram, em suas obras, a necessidade de a Geografia Escolar adequar-se às demandas de um ensino geográfico contextualizado, e capaz de instigar o discente à uma postura atuante na sociedade. 
(...) o enciclopedismo geográfico igualmente concluiu o fenômeno de despolitização do discurso geográfico que consegue tão frequentemente falar da atualidade sem colocar um único problema político. (BRABANT, 2008, p. 19).

A geografia, necessariamente, deve proporcionar a construção de conceitos que possibilitem ao aluno compreender o seu presente e pensar o futuro com responsabilidade, ou ainda, preocupar-se com o futuro através do inconformismo com o presente. (STRAFORINI, 2008, p. 51).

Dentre as possibilidades que proporcionam uma reflexão sobre a promoção da justiça social e participação ativa na sociedade, está a compreensão e assimilação do conceito do multiculturalismo que, grosso modo, compreende a ideia da coexistência de diferentes culturas em um mesmo território. Nesta perspectiva, a questão da equidade não se baseia, simplesmente, e de modo superficial, na busca pela igualdade, mas, principalmente, pelo respeito e valorização das diferenças. É de extrema importância a compreensão desta premissa, pois uma análise superficial do que se entenda por pluralidade pode levar a uma errônea interpretação, que mascara injustiças e sufoca a luta por direitos. Assim, é essencial entender que a luta pela discussão e reflexão acerca das desigualdades nunca deve ser preterida. Esta perspectiva é amplamente reconhecida, por exemplo, em autores como Santos \& Nunes (SANTOS \& NUNES, 2003, p. 25-33):

Como é possível, ao mesmo tempo, exigir que seja reconhecida a diferença, tal como ela se constituiu através da história, e exigir que os "outros" nos olhem como iguais e reconheçam em nós os mesmos direitos de que são titulares? (SANTOS \& NUNES, 2003, p. 25).

A ideia de movimento, de articulação de diferenças, de emergência de configurações culturais baseadas em contribuições de experiências e de histórias distintas tem levado a explorar as possibilidades emancipatórias do multiculturalismo, alimentando os debates e iniciativas sobre novas definições de direitos, de identidades, de justiça e de cidadania. (SANTOS \& NUNES, 2003, p.33)

O risco de uma passividade frente às injustiças sociais e culturais, encobertas por uma equivocada noção de multiculturalismo, tende a oprimir ainda mais as minorais que já não se sentem representadas e, efetivamente, respeitadas, perante o aparente discurso de igualdade. Bauman (BAUMAN, 2005, p. 44) ressalta a opressão vivenciada pelos grupos minoritários:

(...) abarrotam aqueles que tiveram negado o acesso à escolha da identidade, que não têm direito de manifestar as suas preferências e que no final se veem oprimidos por identidades aplicadas e impostas por outros - identidades de que eles próprios se ressentem, mas não têm permissão de abandonar nem das quais conseguem se livrar. 
Identidades que estereotipam, humilham, desumanizam, estigmatizam. (BAUMAN, 2005, p. 44).

Com o advento da globalização, que possibilitou o aumento dos fluxos migratórios internacionais, torna-se cada vez mais pujante a discussão acerca da multiculturalidade nos ambientes educacionais. Tal importância se dá pela consciência e reconhecimento da diversidade cultural existente nas diferentes sociedades no mundo, e dos desafios advindos desta realidade, principalmente no que tange à questão da xenofobia. O próprio Estado, que deveria ser o exemplo do respeito, além de uma referência educadora à sociedade, demonstrou, pelos fatos relatados, o caminho contrário. Tal contradição já era uma percepção evidenciada por Santos (SANTOS, 2002, p. 47), mesmo antes da conjuntura política atual, em que o Estado prega a importância e a valorização da diversidade, mas exerce medidas de homogeneização e sufocamento da pluralidade cultural.

\footnotetext{
Enquanto, externamente, têm sido os arautos da diversidade cultural, da autenticidade da cultura nacional, internamente, têm promovido a homogeneização e a uniformidade, esmagando a rica variedade de culturas locais existentes no território nacional, através do poder da polícia, do direito, do sistema educacional ou dos meios de comunicação social, e na maior parte das vezes por todos eles em conjunto (SANTOS, 2002, p. 47-48).
}

A educação tem, assim o papel de fomentar tais discussões, promovendo a reflexão e, principalmente, a atuação crítica dos sujeitos, visando lutar contra as injustiças, desigualdades e preconceitos decorrentes da realidade de sociedades multiculturais, como a sociedade brasileira. Candau (CANDAU, 2002, p. 55) enfatiza que "os defensores do multiculturalismo em educação se esforçam para reverter esta realidade e enfrentam grandes desafios como o crescimento da intolerância e da xenofobia”. Ora, a interseção de disciplinas, em uma perspectiva transdisciplinar, garantirá a apropriação de conhecimentos que possam gerar reflexões cada vez mais ricas e profícuas, fortalecendo o senso democrático e o desenvolvimento de habilidades - sejam elas linguísticas ou geográficas - capazes de promover o avanço social. Nessa medida, o papel da escola é evidenciado e chamado ao protagonismo.

\section{Considerações finais}

O presente trabalho buscou despertar a possibilidade de contextualização da pandemia do Covid19 em discussões pertinentes às ciências humanas e à linguística. Estudar os discursos com viés xenófobo, que se apresentaram nos últimos tempos, perante a propagação do novo vírus, oferece um campo fértil de análises. As perspectivas possíveis discorrem desde o estudo do discurso em si, na forma em que as informações são apresentadas, bem como nas implicações geopolíticas envolvidas nestas proposições. 
Estas abordagens fazem parte da construção do conhecimento trabalhado na educação básica, por vezes, também, dependendo do enfoque de cada curso, no nível superior. A contextualização dos conteúdos, perante a vivência do aluno, torna a aprendizagem mais significativa, e, a conjuntura atual, em todo o globo, perpassa a pandemia do novo coronavírus.

A importância da contextualização das discussões, que torna os educandos sujeitos mais críticos, é ressaltada pelo reconhecido patrono da educação brasileira, Paulo Freire:

Quanto mais se problematizam os educandos, como seres no mundo e com o mundo, tanto mais se sentirão desafiados. Tão mais desafiados, quanto mais obrigados a responder ao desafio. Desafiados, compreendem o desafio na própria ação de captá-lo. Mas, precisamente porque captam o desafio como um problema em suas conexões com outros, num plano de totalidade e não como algo petrificado, a compreensão resultante tende a tornar-se crescentemente crítica, por isto, cada vez mais desalienada'’. (FREIRE, 2011, p. 98)

Por questões metodológicas, de delimitação de análise, selecionamos discursos que foram amplamente divulgados na mídia, de posicionamentos com cunho xenófobo, por parte de figuras políticas brasileiras. Infelizmente, este tipo de atitude não se restringiu aos representantes brasileiros, mas se evidenciou na conduta de várias personalidades, e de diversas nacionalidades. Até mesmo a China, maior vítima do discurso do ódio no contexto do coronavírus, tem sido denunciada na prática de xenofobia ${ }^{\text {viii }}$. O intuito do trabalho foi alinhavar uma situação atual, realidade para discentes não só do Brasil, mas de todo mundo, com a função universal da educação de promover esclarecimento, conhecimento, reflexão e crítica.

\begin{abstract}
A criticidade para nós implica na apropriação crescente pelo homem de sua posição no contexto. Implica na inserção, na sua integração, na representação objetiva da realidade. Daí a conscientização ser o desenvolvimento da tomada de consciência. Não será por isso mesmo apenas resultante das modificações econômicas, por grandes e importantes que sejam. A criticidade, como entendemos, há de resultar de trabalhos pedagógicos crítico, apoiado em condições históricas propícias. (FREIRE, 1991, p. 69).
\end{abstract}

A educação, na sua missão de conscientização crítica dos indivíduos, objetiva a construção de uma sociedade mais justa e igualitária, onde os povos possam conviver em harmonia e respeito. E foi este, despretensiosamente, o objetivo de colaboração deste trabalho.

\title{
REFERÊNCIAS:
}

ARAÚJO, Ernesto (ernestofaraujo). 19 mar. 2020, 14:05. Tweet. Disponível em:<https://twitter.com/ernestofaraujo/status/1240685730453524480>. Acesso em: 14 mai. 2020. 
ARAÚJO, E. Chegou o Comunavírus. Metapolitica 17. 22 abr. 2020. Disponível em: $<$ https://www.metapoliticabrasil.com/post/chegou-o-comunav\%C3\%ADrus $>$. Acessoem: 20 mai. 2020.

AIXIN, Li. Brazilian president reprimands son for scapegoating China. Global Times. 22 mar.2020. Disponível em:< http://www.globaltimes.cn/content/1183333.shtml>. Acesso em: 17 mai. 2020.

BAUMAN, Zygmunt. Identidade: entrevista a Benedetto Vecchi. Tradução Carlos Alberto Medeiros. Rio de Janeiro: Jorge Zahar Editor, 2005.

BAKHTIN, M. Marxismo e Filosofia da Linguagem. São Paulo: Hucitec, 2010.

BOLSONARO, Eduardo (BolsonaroSP).18 mar. 2020, 14:38. Tweet. Disponível em:<https://twitter.com/BolsonaroSP/status/1240286560953815040>. Acesso em: 14 mai. 2020.

BRABANT, J. M. Crise da Geografia, Crise da Escola. In VESENTINI, José William. Para onde vai o ensino de geografia? 9 ed. São Paulo: Contexto, 2008.

CANDAU, Vera Maria F. Sociedade, cotidiano escolar e cultura (s): Uma aproximação. Educação e Sociedade: Dossiê Diferenças. Revista quadrimestral de ciência da educação, agosto/2002.

CHARAudeau, P.; MAIngueneAU, D. Dicionário de Análise do Discurso. São Paulo: Contexto, 2006.

CILO, Hugo. A piada sem graça de Weintraub. Isto É Dinheiro. 10 abr. 2020. Disponível $\mathrm{em}:<\mathrm{https}: / /$ www.istoedinheiro.com.br/a-piada-sem-graca-de-weintraub/>. Acesso em: 17 mai. 2020.

ORGANIZAÇÃO DAS NAÇÕES UNIDAS. Devemos agir para fortalecer a imunidade das sociedades contra o vírus do ódio. 14 mai. 2020. Disponível em: $<$ https://nacoesunidas.org/onu-devemos-agir-parafortalecer-a-imunidade-das-sociedades-contra-o-virus-do-odio//>. Acesso em: 16 mai. 2020.

Discurso de ódio contra China cresce de forma alarmante no Twitter por coronavírus. Carta Capital. 28 mar.2020. Disponível em: $<$ https://www.cartacapital.com.br/mundo/discurso-de-odio-contra-china-crescede-forma-alarmante-no-twitter-por-coronavirus/>. Acesso em: 15 mai. 2020.

Embaixada da China no Brasil (EmbaixadadaChina). 18 mar. 2020, 22:54. Tweet. Disponível em: $<$ https://twitter.com/EmbaixadaChina/status/1240456558007508993>. Acesso em: 14 mai. 2020.

FAUCONNIER, G.; TURNER, M. The Way We Think. New York: Basic Books, 2002.

FREIRE, Paulo. A educação na cidade. São Paulo: Cortez, 1991.

. Pedagogia do Oprimido. Rio de Janeiro: Paz e Terra, 2011.

GÓIS, V. O direito à informação jornalística. São Paulo: Intermédios, 2012.

SÁ, Nelson. Mídia chinesa vê 'xenofobia' e 'loucura' em Eduardo Bolsonaro. Folha de São Paulo. São Paulo, 19 mar. 2020. Disponível em: $<$ https://www1.folha.uol.com.br/colunas/nelsondesa/2020/03/midiachinesa-ve-xenofobia-e-loucura-em-eduardo-bolsonaro.shtml?origin=folha/ $>$. Acesso em: 15 mai. 2020.

SANTOS, C. Série: Assistente Social no combate ao preconceito. Caderno 5, Brasília (DF), 2016. CFESS (Conselho Federal de Serviço Social). 
SANTOS, Milton. Por uma outra globalização - do pensamento único à consciência universal. Rio de Janeiro: Record, 2006.

SANTOS, Boaventura de Sousa. NUNES, João Arriscado. Introdução: para ampliar o cânone do reconhecimento, da diferença e da igualdade. In: SANTOS, Boaventura de Sousa (org.). Reconhecer para libertar: os caminhos do cosmopolitismo multicultural. Rio de Janeiro: Civilização Brasileira, 2003 (Série Reinventar a emancipação social: para novos manifestos, v. 3).

SANTOS, Boaventura de Sousa. Os processos da globalização. In: SANTOS, Boaventura de Sousa (org.). A globalização e as ciências sociais. 2 ed. São Paulo: Cortez, 2002.

STRAFORINI, R. Ensinar Geografia: o desafio da totalidade: mundo nas séries iniciais. 2 ed. São Paulo: Annablume, 2008.

WANMING, Yang (WanmingYang). 18 mar. 2020, 21:55. Tweet. Disponível em:<https://twitter.com/WanmingYang/status/1240441812105519109>. Acesso em: 4 mai. 2020.

${ }^{i}$ Doutor em Linguística, graduado em Letras e Pedagogia. Centro Universitário UNA, Belo Horizonte. Email: rteixeirapl@gmail.com. Minas Gerais. ORCID: https://orcid.org/0000-0002-8348-1326.

ii Especialista em Gestão Pedagógica, graduada em Geografia. Colégio Santa Dorotéia, Belo Horizonte. E-mail: joyce.pedra@gmail.com. Minas Gerais. ORCID: https://orcid.org/0000-0001-6482-9035.

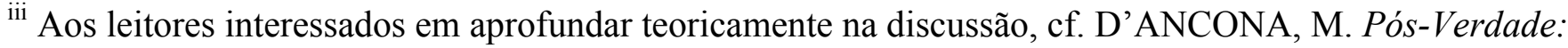
A nova guerra contra os fatos em tempos de fake news. São Paulo: Faro Editorial, 2018.

iv Termo utilizado para se referir ao processo de saída do Reino Unido da União Europeia.

${ }^{v} \mathrm{O}$ termo aqui está sendo usado em seu rigor etimológico, isto é, vinculado à dimensão retórica ancorada em pathos. Ao leitor interessado, cf. ARISTOTLE. Rhetoric. London: Harvard University , 1926.

vi "De acordo com membros da imprensa brasileira, o presidente brasileiro Jair Bolsonaro estava insatisfeito com as declarações hostis de seu filho sobre a China e repreendeu o Bolsonaro mais jovem sobre o assunto. O presidente do Senado, Davi Alcolumbre, e o presidente da Câmara dos Deputados, Rodrigo Maia, também pediram desculpas ao governo e ao povo chinês no Twitter nesta quinta-feira, criticando as observações inapropriadas feitas por Eduardo Bolsonaro, que são contrárias à significante parceria estratégia entre China e Brasil.Alcolumbre, que deu positivo para o coronavírus, disse: "Reações isoladas não representam o sentimento da nação", em nome do parlamento brasileiro no Twitter. "Em nome da Câmara dos Deputados, peço desculpas à China e ao embaixador [chinês] Yang Wanming pelas palavras imprudentes do congressista Eduardo Bolsonaro", twittou Maia. "Espero que em breve possamos sair da crise atual ainda mais forte", disse ele".

${ }^{\text {vii }} \mathrm{O}$ ministro Abraham Weintraub apagou a referida postagem do seu Twitter.

viii Tal prática tem ocorrido no contexto do receio de que estrangeiros possam ser responsáveis por uma nova fase de propagação do Covid-19, após a contenção local do vírus. Somada a esta situação, há indícios de que a xenofobia é intensificada no país quando o estrangeiro é africano. Ao leitor interessado, cf. https://www1.folha.uol.com.br/mundo/2020/04/xenofobia-contra-africanos-na-china-gera-crisediplomatica-entre-pequim-e-aliados.shtml 